\title{
Archivos y procesos creativo-expositivos: una reflexión museológica sobre la violencia en los proyectos recientes de la artista Ioulia Akhmadeeva en Michoacán, México
}

Creative and Exhibitionary Archives and Processes: a Museological Analysis on the Violence in Recent Projects by Artist loulia Akhmadeeva in Michoacan, Mexico

\section{Eugenia Macías Guzmán}

Museo Morelense de Arte Contemporáneo (MMAC) "Juan Soriano", México eugenia.macias@gmail.com

\section{Resumen}

Con base en conceptos teóricos museológicos y curatoriales, este ENSAYO analiza el papel de diversos acervos documentales y visuales, y del archivo biográfico de la artista rusa loulia Akhmadeeva, quien los empleó como herramientas creativas para tratar distintos casos de violencia social acaecidos tanto en su país natal como en México y otras naciones: Alemania, Siria y Ucrania, dentro del núcleo denominado "Muerte y pacifismo" de su muestra retrospectiva Desde y para la memoria, inaugurada en el 2015 en el Museo de Arte Contemporáneo "Alfredo Zalce", Michoacán, México. Esta exposición mostró los materiales de archivo en diálogo, en contrapunto o a una sola voz con algunos de sus libros de artista y un nuevo proyecto de libro-instalación, con la finalidad de visualizar y problematizar procesos violentos en esas diversas regiones del planeta. Mediante la combinación de análisis museológico, visual y de contenidos de la muestra con contribuciones de la libreta de comentarios de ella, testimonios de jóvenes estudiantes universitarios en Morelia sobre su experiencia al mirarla, este ENSAYO propone una meditación teórica actual sobre el papel del archivo en el arte contemporáneo y los sucesos violentos resignificados por la autora en la propia exposición. Con ello, se busca avanzar en la discusión acerca de la aportación de la exhibición y de la reflexión museográfica en la indagación, el posicionamiento y el diálogo político que se generan en la exploración de la memoria y la violencia.

\section{Palabras clave}

Ioulia Akhmadeeva; arte contemporáneo; museología; curaduría; violencia; libro-objeto; Michoacán; México

\section{Abstract}

Based on theoretical museological and curatorial concepts, this ESSAY analyses the role of different document and visual archives, and of the biographical archive of Russian artist loulia Akhmadeeva, who used them as creative tools to address different cases of social violence occurred in 
her own country, in Mexico and in other nations, such as: Germany, Syria, and Ukraine, within the curatorial nucleus called "Muerte y Pacifismo" ("Death and Pacifism") of her retrospective exhibition Desde y para la memoria (From and for remembrance), inaugurated in 2015 in the Museo de Arte Contemporáneo "Alfredo Zalce" (Contemporary Art Museum "Alfredo Zalce"), Michoacan, Mexico. This exhibition showed the archive materials in the form of dialogue, counterpoint, or in a single voice, with some of her artist books and a new book-installment project, in order to visualize and problematize the violent processes in these different regions of the world. Henceforth, by combining museological, visual, and content analysis of the exhibition with contributions from the commentary notes of the artist, the testimonies of young university students in Morelia regarding their experience when observing the exhibition, this ESSAY poses a current theoretical examination on the role of the archive in contemporary art, as well as information on the violent events that were redefined by the author in the same exhibition. With this, it seeks to develop the discussion on the contributions of the exhibition and of the museographic reflection in the political inquiry, on the positioning, and on the dialogue generated in the exploration of remembrance and violence.

\section{Key words}

Ioulia Akhmadeeva; contemporary art; museology; curatorship; violence; book-object; Michoacan; Mexico

Introducción: el núcleo curatorial "Muerte y pacifismo" de la exposición Desde y para la memoria, Museo de Arte Contemporáneo "Alfredo Zalce", Michoacán, México

2 Puede una exposición que expande disciplinas y posibilidades plásticas impulsar una conciencia que incluso participe en cambios sociales en algunos de los espectadores que la miran?

¿En qué medida las exhibiciones de nuevas prácticas artísticas plásticas con el tema de la violencia detonan posicionamientos políticos?

¿Cómo contribuyen a esto las experimentaciones que ponen en diálogo la memoria de procesos violentos, los archivos y la gráfica expandida a soluciones expresivas tridimensionales?

¿En qué contribuye una reflexión museológica de un proyecto expositivo con los rasgos mencionados a desvelar las indagaciones enunciadas?

Estas preguntas han rondado el presente texto, que reflexiona sobre el proceso en que la artista visual loulia Akhmadeeva (1971) puso en práctica entre octubre del 2015 y enero del 2016 a lo largo del proyecto expositivo Desde y para la memoria, presentado en el Museo de Arte Contemporáneo "Alfredo Zalce", de la Secretaría deCultura del Estado de Michoacán, en la ciudad capital de ese estado, Morelia, México. Esta iniciativa conjuntó los proyectos realizados por la artista entre el 2014 y el 2015 con el apoyo del Programa de Estímulo a la Creación y al Desarrollo Artístico de Michoacán, del Consejo Nacional para la Cultura y las Artes (PECDAM-Conaculta), con su invitación a colaborar en diálogo en la elaboración de la curaduría de la muestra.

Akhmadeeva, con una importante trayectoria en prácticas gráficas, durante la cual ha formado, desde hace más de 10 años, artistas en el taller de grabado de la Escuela Popular de Bellas Artes de la Universidad Michoacana de San Nicolás de Hidalgo (UMSNH), México (Akhmadeeva 2015-2017), al ser una activa difusora de esta vertiente aplicada en arte-objeto y libro de artista, en México y diversos países (cfr. Akhmadeeva 2015-2017), se desbordó de la gráfica en la exposición Desde y para la memoria. Por necesidades expresivas, en esta muestra la artista fusionó al grabado con otras prácticas artísticas para desarrollar el tema de la memoria, noción que, en el manejo libre de esta creadora, se concibe como la facultad mental que deriva de la experiencia aprehendida de procesos vividos en viajes, por transmisión familiar intergeneracional y de violencia (cfr. Akhmadeeva 2015).

En términos compositivos, Desde y para la memoria contó con un área introductoria con proyectos diversos (16 años: 1998-2014, Borders I-IV, Sobre el cielo y Casaspájaro), emblemáticos de las indagaciones que se desarrollarían en los siguientes núcleos curatoriales: a) "Via$\mathrm{je}$ ", b) "Generaciones, resonancias, desdoblamientos", c) "Transferido, encapsulado, registrado y lo redondo", y, finalmente, $d$ ) "Muerte y pacifismo" (Figura 1).

La exposición antes referida destaca debido a que, en su desarrollo curatorial, Akhmadeeva (cfr. 2015-2017) se desmarcó de sus fórmulas artísticas habituales, hasta entonces caracterizadas por experimentaciones de diversas técnicas de gráfica en obras bidimensionales o en libros de artista, para hablar plena y críticamente de los asedios contemporáneos y desarrollar indagaciones sobre el libro de artista y la gráfica expandida a lo tridimensional, como prácticas creativas que ella vive como "simbiosis compleja de múltiples combinaciones de distintos lenguajes y sistemas de comunicación" (Akhmadeeva 2015:7). En concurrencia, este ENSAYO describirá y analizará el núcleo "Muerte y pacifismo" de la citada muestra, de forma conjunta con las implicaciones museológicas de su montaje, el cual puso en diálogo los archivos audiovisuales y fotográficos de procesos violentos a escala mundial y, concretamente, los sucedidos en México, con la gráfica y el libro de artista como prácticas creativas comunicativas-reflexivas. A la par de investigar qué implica divulgar estos sucesos en un estado como Michoacán, México, fuertemente afectado por la violencia relacionada con el narcotráfico en los últimos años (cfr. Calderón 2015; Quesada 2015), aquí se reflexiona sobre el papel discursivo que tuvo el archivo personal y la consulta y puesta a la vista de acervos documentales diversos en estos procesos creativos. El estudio se complementa con una investigación documental acerca de la teoría actual sobre museología, los archivos y las prácticas artísticas 


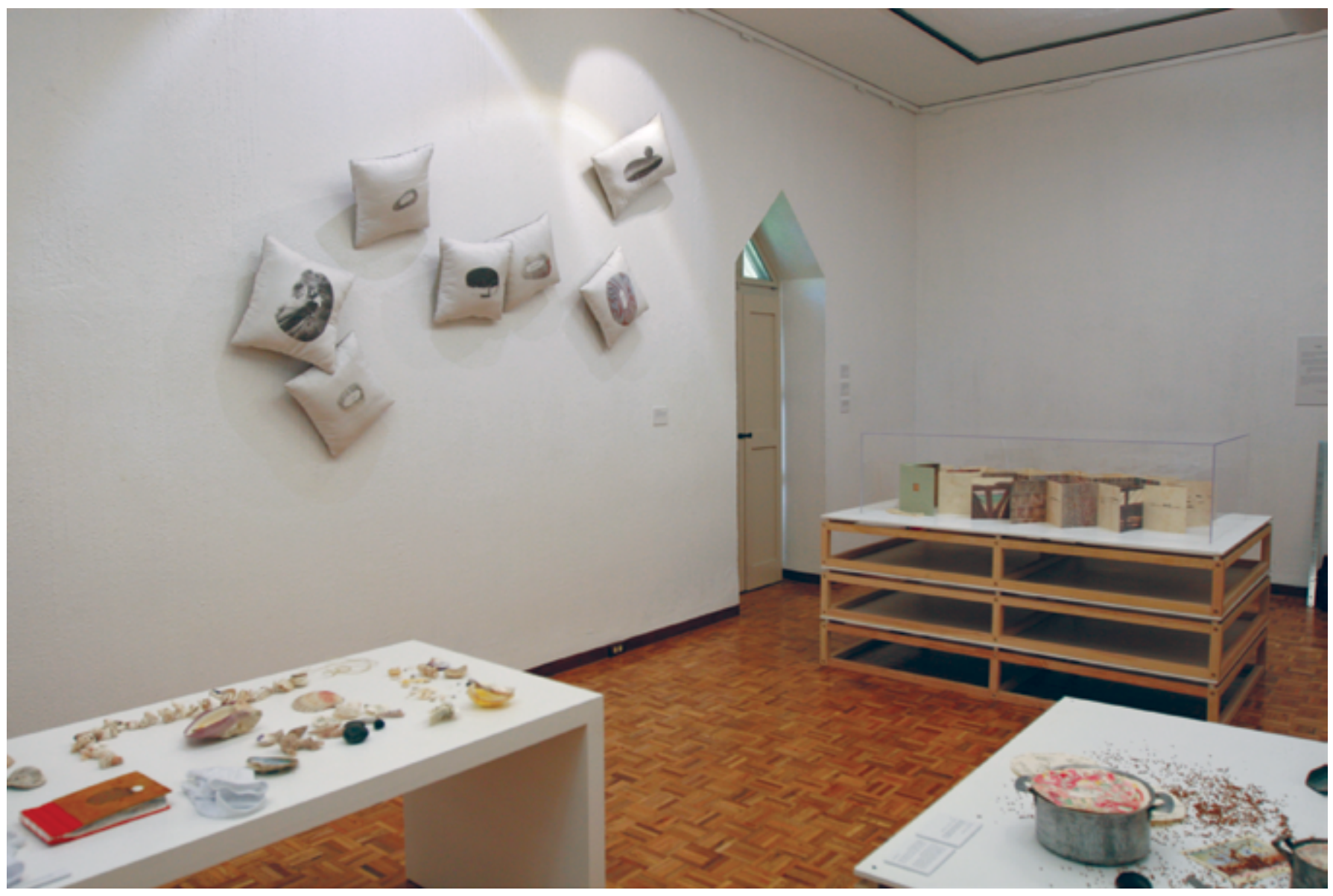

FIGURA 1. Exposición Desde y para la memoria. Ioulia Akhmadeeva, 2015 (Fotografía: Alternativa Gráfica, 2015; cortesía: loulia Akhmadeeva).

contemporáneas, así como con la recuperación de testimonios de la libreta de comentarios de la muestra y las entrevistas que, en marzo del 2016, se les hicieron a tres jóvenes estudiantes de historia del arte en la Escuela Nacional de Estudios Superiores (ENES)-Unidad Morelia, de la Universidad Nacional Autónoma de México (UNAM), de entre 19 y 22 años de edad, que acudieron a la exposición. Dos de ellos son originarios de la Ciudad de Méxi$\mathrm{Co}$, aunque radican en Morelia por razón de sus estudios, mientras que el tercero es oriundo de esa ciudad. El guion que sirvió para interrogarlos retoma metodología reciente de la antropología lingüística que ha postulado la diversificación del tradicional esquema pregunta-respuesta de la entrevista con dispositivos de interacción con las personas que las inviten a hacer actividades en las que despliegan o expresan lo que les es significativo del fenómeno estudiado (cfr. Ochs y Schieffelin 1997:251-260; Duranti 2000:377-421; Goffman 1983:128-157; Foley 1997:3-25). Con base en tales premisas, en la interacción con los estudiantes se trataron los siguientes aspectos: 1) recrear una explicación para alguien cercano del núcleo "Muerte y pacifismo"; 2) generar tres frases de apreciación de los proyectos del núcleo, a saber: Bukvar, Libro híbrido y Día de conocimiento; 3) reflexionar sobre la relación entre los materiales de archivo y los proyectos re- feridos; 4) vincular estos aspectos con la historia reciente del estado de Michoacán, México.

\section{Archivos del núcleo "Muerte y pacifismo". Lo documental dentro de procesos expresivos}

A lo largo de la exposición Desde y para la memoria, los materiales archivados o recolectados cobran un papel fundamental como herramienta de expansión de sentido de los proyectos. En uno de sus núcleos: "Muerte y pacifismo", un primer elemento lo componía una vitrina con materiales de entre 1978 y 1985: fotografías, reconocimientos y cuadernos de primer año de educación básica pertenecientes a la artista, como cuadernos de ruso con dictados sobre próceres - por ejemplo, Vladimir Ilich Uliánov, alias Lenin (1870-1924)—, revistas infantiles, una de ellas, dedicada a la Armada soviética y materiales de los campamentos infantiles "Artek" en Crimea, Ucrania, URSS (Figura 2).

En el segundo plano de esta zona se colocó un monitor con un montaje audiovisual de 23 minutos de duración que contenía fragmentos documentales en torno de la masacre de niños y jóvenes en la escuela primaria núm. 1 de Beslán, en Osetia, Rusia, perpetrado el 3 de septiembre de 2004, que comenzó el 1 de septiembre 


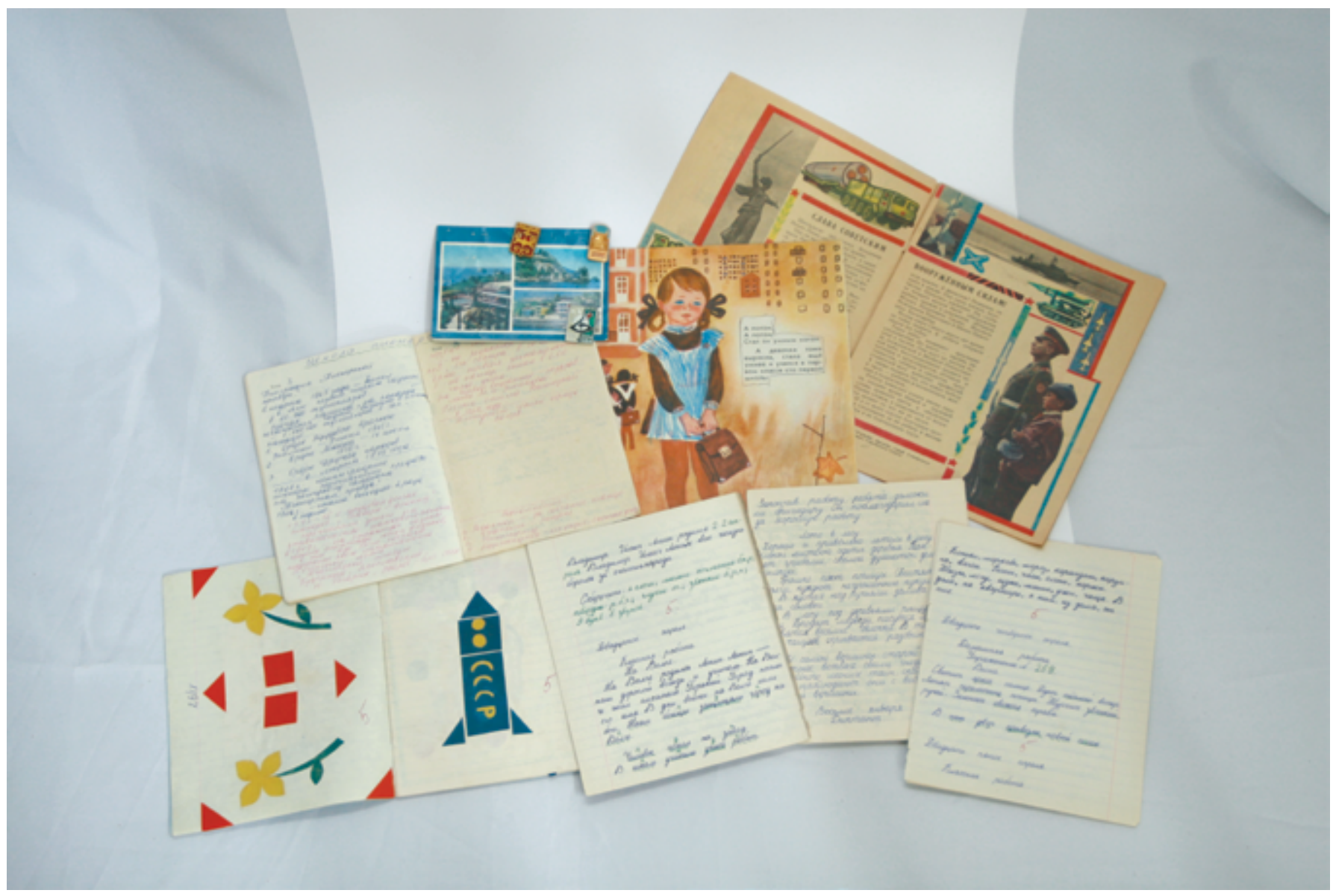

FIGURA 2. Fotografías, reconocimientos y cuadernos del primer año de primaria de loulia Akhmadeeva, 1978 (Fotografía: Alternativa Gráfica, 2015 ; cortesía: Ioulia Akhmadeeva).

con el sitio de este centro educativo (McAllister y QuinnJudg 2004; Paton y Beaumont 2004), así como de otras matanzas, asesinatos, genocidios, exilios y precariedades en Medio Oriente, Europa y América durante el siglo pasado y aún en años recientes (Figura 3).

Una somera revisión de estos sucesos violentos que la artista recupera en los proyectos creativos que trata en este núcleo expositivo hace ver la densidad de información y prácticas en torno de ellos, y puede ser útil para la comprensión del diálogo archivo-materia creativa que activó loulia Akhmadeeva. Detenerse reflexivamente en ellos ayuda a no normalizarlos en la vorágine de la ostensibilidad contemporánea de la imagen y la información. También invita a problematizar en términos museológicos, es decir, a plantear diversas actividades, como, por ejemplo, reflexionar el caso específico de un núcleo curatorial y su montaje en una exposición dentro de un museo, meditar cuán eficaces son los dispositivos expresivos que la artista propuso en ese núcleo curatorial, para, así, hacer conciencia de la fuerza de la violencia que las nuevas generaciones sufren una y otra vez en cada época en distintas partes del mundo, teniendo en mente la pregunta crítica: ¿este exceso de revisión de la violencia, puesto al alcance de los espectadores, incita en ellos su participación en algún proceso de cambio social efectivo que contribuya a revertir atropellos a los derechos humanos?

Uno de los sucesos, que tiene una importancia central en la pieza protagónica del núcleo curatorial "Muerte y pacifismo", retomado por loulia Akhmadeeva, es la masacre de la primaria antes mencionada, que sucedió el 3 de septiembre de 2004 tras de que militantes suicidas islámicos de origen checheno e ingusetio que reivindicaban la independencia y la desocupación rusa de Chechenia tomaron ese centro escolar; hubo más de 300 muertos, 150 desaparecidos y 700 heridos (cfr. McAllister y Quinn-Judg 2004; Paton y Beaumont 2004).

Otro de los hechos históricos que cita Akhmadeeva en "Muerte y pacifismo" son los campos de trabajo en Rusia que pertenecían a la Dirección General de Campos de Trabajo (GULAG, por sus siglas en ruso): formalizados en 1930 (aunque ya estaban activos años antes) y disueltos en 1960. De acuerdo con la documentación periodística de Conquest (1997), albergaban a quienes se consideraban amenazas al Estado soviético: criminales, presos políticos, miembros de la Iglesia ortodoxa rusa, sectores que podían incluir mujeres y sus niños (Conquest 1997). La información del periodista de marras expone que los campos eran represivos, correctivos y explotaban laboral- 


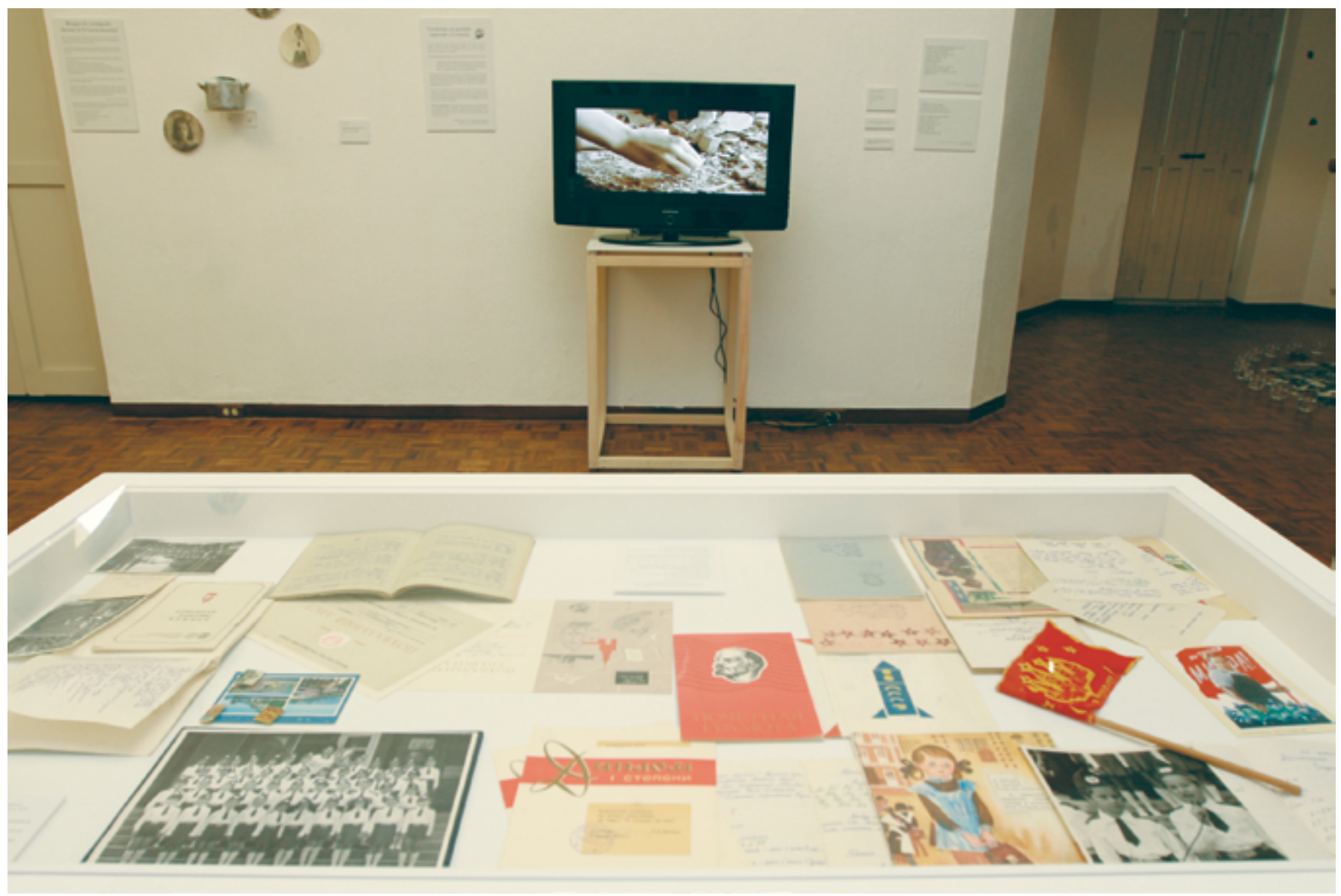

FIGURA 3. Día de Conocimiento. Montaje audiovisual. Idea y guion: Ioulia Akhmadeeva. Edición y montaje: Alexandro Maldonado, 2015. Fotografías, reconocimientos y cuadernos del primer año de primaria de loulia Akhmadeeva, 1978 (Fotografía: Alternativa Gráfica, 2015; cortesía: loulia Akhmadeeva).

mente a estos grupos estigmatizados con el fin de extraer recursos naturales, colonizar áreas remotas, construir infraestructura e industria y reforzar nuevas políticas económicas de la URSS, empresa dirigida por Joseph V. Stalin, vivo entre 1878 y 1953 (Conquest 1997).

Otro proceso al que alude Akhmadeeva en "Muerte y pacifismo" son los campos de concentración nazis que se construyeron y funcionaron entre 1938 y 1945 como parte de un plan de genocidio de población judía durante la Segunda Guerra Mundial, donde su estancia final en ellos fueron la fase final de la aprehensión, deportación, traslado y forzamiento a duros trabajos (Jewish Virtual Library s.f.).

Conforme a Sánchez Herráez (2015) y Colas (2015), los conflictos armados en la zona de Donbass, Ucrania, también conocidos como Guerra Civil en el este de Ucrania, se dieron como manifestaciones y enfrentamientos armados en favor de Rusia en la primera mitad del 2014 en contra de un nuevo gobierno ucraniano establecido en Kiev, que desembocó en la guerra entre fuerzas independentistas de Donetsk y Lugansk contra el gobierno oficial ucraniano, apoyadas por paramilitares rusos, y el tráfico ilegal de armas disimulado en transportes humanitarios que transitaban en la zona.
Éstos son otros de los sucesos rememorados por la artista, que, en nuestras sesiones de trabajo acerca del proyecto expositivo (Akhmadeeva 2015: comunicación personal), se nutrió de los comentarios en cuanto a que su familia es originaria de esa región ucraniana.

La actual guerra civil en Siria es otro conflicto internacional que a loulia Akhmadeeva le interesó incluir en la información desplegada en "Muerte y pacifismo". De acuerdo con reportajes de Zetter y Ruaudel (2014), más los de la BBC, sección Mundo (2015), durante el 2014 se incrementó a miles por día el número de refugiados sirios que huían de dicho conflicto armado en su nación, desplazándose a países como Líbano, Jordania e Iraq. Hacia septiembre del año siguiente, la expansión de la migración de estas poblaciones hacia Europa entró en fase crítica debido a su acelerado aumento; en esas fechas comenzó, asimismo, a extenderse hacia América (cfr. Zetter y Ruaudel 2014; Redacción BBC Mundo 2015).

En distintas sesiones de trabajo que sostuve con loulia Akhmadeeva desde el inicio del proyecto expositivo, ella mencionaba que la desaparición forzada de estudiantes de la Escuela Normal Rural Isidro Burgos, de Ayotzinapa, Guerrero, México, contribuyó — por estar más cercano este suceso a su vida cotidiana, y por impresión e indig- 
nación- a su necesidad de dedicar un núcleo expositivo al tema de la violencia contemporánea en su proyecto Desde y para la memoria (Akhmadeeva 2015: comunicación personal).

Como lo ha documentado Sergio René de Dios Corona (2014), las desapariciones de estudiantes de Ayotzinapa ocurrieron entre el 26 y 27 de septiembre de 2014 como resultado de enfrentamientos entre policías de ese municipio y cerca de 100 estudiantes de la escuela de formación de maestros rurales, que tomaron camiones para acudir al aniversario de la matanza del 2 de octubre de 1968 en Tlatelolco, en la Ciudad de México (Corona 2014). Tras dos fuertes enfrentamientos la noche del 26 de septiembre, al intentar irrumpir las actividades civiles festivas encabezadas por el presidente municipal de Iguala, José Luis Abarca, y su esposa, María de los Ángeles Pineda, murieron algunos estudiantes, mientras que otros se dispersaron y regresaron a sus casas (Corona 2014). En la mañana del 27 de septiembre se encontró el cuerpo, con rastros de desollamiento, de uno de ellos, lo cual dio visibilidad ineludible al conflicto, las desapariciones y los heridos (Corona 2014).

En noviembre se presentó un informe oficial de la Procuraduría General de la República de México, que rechazó gran parte de la sociedad civil, con lo que una comisión de activistas y familiares de los desaparecidos solicitó al Grupo Interdisciplinario de Especialistas Independientes (GIEI) de la Comisión Interamericana de Derechos Humanos (CIDH) que realizara un nuevo estudio, el cual, en septiembre del 2015, comentó aquel primer informe oficial. El caso sigue sin esclarecerse (Corona 2014).

En este contexto, vale la pena subrayar la desaparición de Gilberto Abundiz Sánchez, el 30 de marzo de 2015, en la cabecera municipal de Chilapa, en el estado de Guerrero, México, lugar del que era oriundo y en el que reside su familia. Casi dos meses después se identificó su cuerpo sin vida mediante reconocimiento genético entre restos de tres cuerpos hallados en la localidad de Nejapa, Guerrero, cerca de Chilapa (Pigeonutt 2015). Abundiz era artista visual con estudios en la Escuela Popular de Bellas Artes de la Universidad Michoacana de San Nicolás Hidalgo (UMSNH), en Morelia, donde residía, como lo afirmó Akhmadeeva al relatarme lo sucedido con él en una de nuestras sesiones de trabajo, pues había sido su alumno y colaboraba con ella en varios proyectos hasta el día de su desaparición (Akhmadeeva 2015: comunicación personal). En la mencionada escuela de la UMSNH, Akhmadeeva y otros artistas organizaron, en septiembre del 2015, una marcha y una exposición homenaje a la que llamaron Maldía, título que alude a la fecha del secuestro de Abundiz. La creadora (Akhmadeeva 2015: comunicación personal) me relató que ella y los demás artistas, así como familiares y amigos cercanos, creen que Abundiz realizaba un proyecto de videoarte en Chilapa en el que retomaba prácticas, colorido, texturas y lugares, y que quizá algunos grupos delictivos de ese entonces (marzo del 2015) lo detectaron en la zona haciendo registros audiovisuales y, por creer que hacía algún tipo de pesquisa contra ellos, lo desaparecieron. En mi opinión, esto, no aclarado todavía, suscita la reflexión de cuántas muertes de este tipo suceden día a día en el México actual y quedan sin resolverse por ser cuestiones de pequeña escala en relación con otros sucesos de mayor notoriedad.

Es probable que el lector haya Ilegado hasta aquí saturado de este gravoso recuento y preguntándose para qué se presenta en estas páginas. Sólo enlistar estos sucesos no sería tratar con dignidad a sus víctimas. Y esta información, aunque breve, brinda un panorama del peso de estos conflictos sociales, que es también un agente comunicativo operante en el núcleo "Muerte y pacifismo" que analizamos en este texto. En diversas sesiones de trabajo, loulia Akhmadeeva (2015: comunicación personal) expresó que parte de la conciencia que quería despertar en esta área de la exposición consistía en contagiar al público sobre la densidad de estos acontecimientos por el sólo mirarlos, escucharlos y recorrerlos de algún modo en los dispositivos expresivos que ella creó.

En este tenor, loulia Akhmadeeva alude a su pieza más importante en ese núcleo curatorial: Día de conocimiento (2015), libro-instalación, en el que diversas prácticas gráficas y de impresión se conjugan en un ensamblaje y recolección de elementos objetuales diversos para conformar un área de homenaje a niños y jóvenes masacrados por terroristas en la nombrada primaria de Beslán, Rusia. La artista rememora también los niños en los GULAG en ese país, los infantes que murieron en enfrentamientos paramilitares en Donbass, Ucrania, la huida de niños de Siria, los 43 estudiantes desaparecidos en Ayotzinapa, en el estado de Guerrero, en México, y, especialmente, el joven artista Gilberto Abundiz, su alumno en la UMSNH, secuestrado y asesinado en el 2015.

Repasar aquí brevemente los procesos de estos sucesos incorporados en los proyectos del núcleo "Muerte y pacifismo" es una invitación a no tomarlos solamente desde lo aparente visual de las piezas y los recursos museográficos en la exposición, sino incentivando operaciones de reflexividad sensible postuladas por la vertiente reciente de museología crítica (cfr. Hernández 2007; Foster 2015). Por ejemplo, en relación con las curadurías y los procesos expositivos que Francisca Hernández (cfr. 2007:4, 5, 9, 10, 11) ha estudiado a detalle, se ha indagado en la discursividad interna de los temas y piezas que los integran (Hernández 2007:4, 5, 9, 10, 11). Asimismo, Hal Foster (cfr. 2015:31-35) ha analizado hace poco tiempo prácticas de "arte archivístico" de creadores como Thomas Hirschhorn (Suiza,1957), Tacita Dean (Reino Unido, 1965), Joaquim Koester (Dinamarca, 1962), Sam Durant (EE. UU., 1961) y Jeremy Deller (Reino Unido, 1966), entre otros. 
En las perspectivas teóricas de Foster (2015) también pueden enmarcarse las intervenciones de loulia Akhmadeeva en otras piezas de este núcleo de su proyecto expositivo, que recupera fotografías y materiales audiovisuales documentales: la concepción ampliada de archivo que incluye trazas materiales de información asentadas en cualquier tipo de soportes, que los artistas hacen físicamente presentes en sus proyectos, una vez más, con narrativas visuales articuladas en proyecciones de imágenes que en el arreglo particular que el artista decide se disturban o redireccionan al trasladarse del hallazgo del creador a un ámbito colectivo actual con finalidades relacionales entre aquél y el público para generar espacios expositivos diferentes en los que el pensamiento de los espectadores se mueva, asimismo, a nuevos lugares reflexivos (Foster 2015:31-35).

El material visual del video con grabaciones de los sucesos violentos referidos en este núcleo no presentaba el sonido de los incidentes, sino que estaba acompañado por un audio con diversas canciones pacifistas de la niñez de la artista, cantadas por coros infantiles, cuyas letras, traducidas al español por ella, se incluyeron en un muro, entremezcladas con algunas fotografías de esa etapa de la vida de la autora, más otras de algunos de los sucesos violentos a lo largo del siglo XX, ya mencionados anteriormente, que también se exhiben en el audiovisual (Figura 4).

Las letras de las canciones pacifistas presentan frases como "guerras cayeron en la oscuridad" (Poperechny 1974, en Akhmadeeva 2015:79), o "los niños deben reírse y vivir en la paz" (Pliatskovsky 1980, en Akhmadeeva 2015:79), que, por su contraste con los materiales visuales, que exhibían seres humanos vejados, maltratados, heridos, desplazados, muertos, en situación de calle u otros tipos de precariedad, al ritmo de melodías y voces infantiles optimistas, intensificaban, por la contraposición expresiva entre el carácter de las imágenes y el de la música, la denuncia de violencia articulada en esta sección de la exposición.

Complementariamente, como elemento de apoyo museográfico, se transcribieron en un muro, con vinil, algunos fragmentos recuperados por la artista, traducidos por Gustavo Troncoso, del testimonio de Agunda Bataeva, de 16 años, alumna sobreviviente de la mencionada escuela de Beslán, en el que rememoraba su gusto por la fiesta del Día de conocimiento cada primer día de septiembre en Rusia, los preparativos en su arreglo personal, el traslado al centro escolar con su madre, que era maestra, y la forma en que la ayudó en las últimas tareas previas a la conmemoración; luego, el inicio del sitio, su pro-

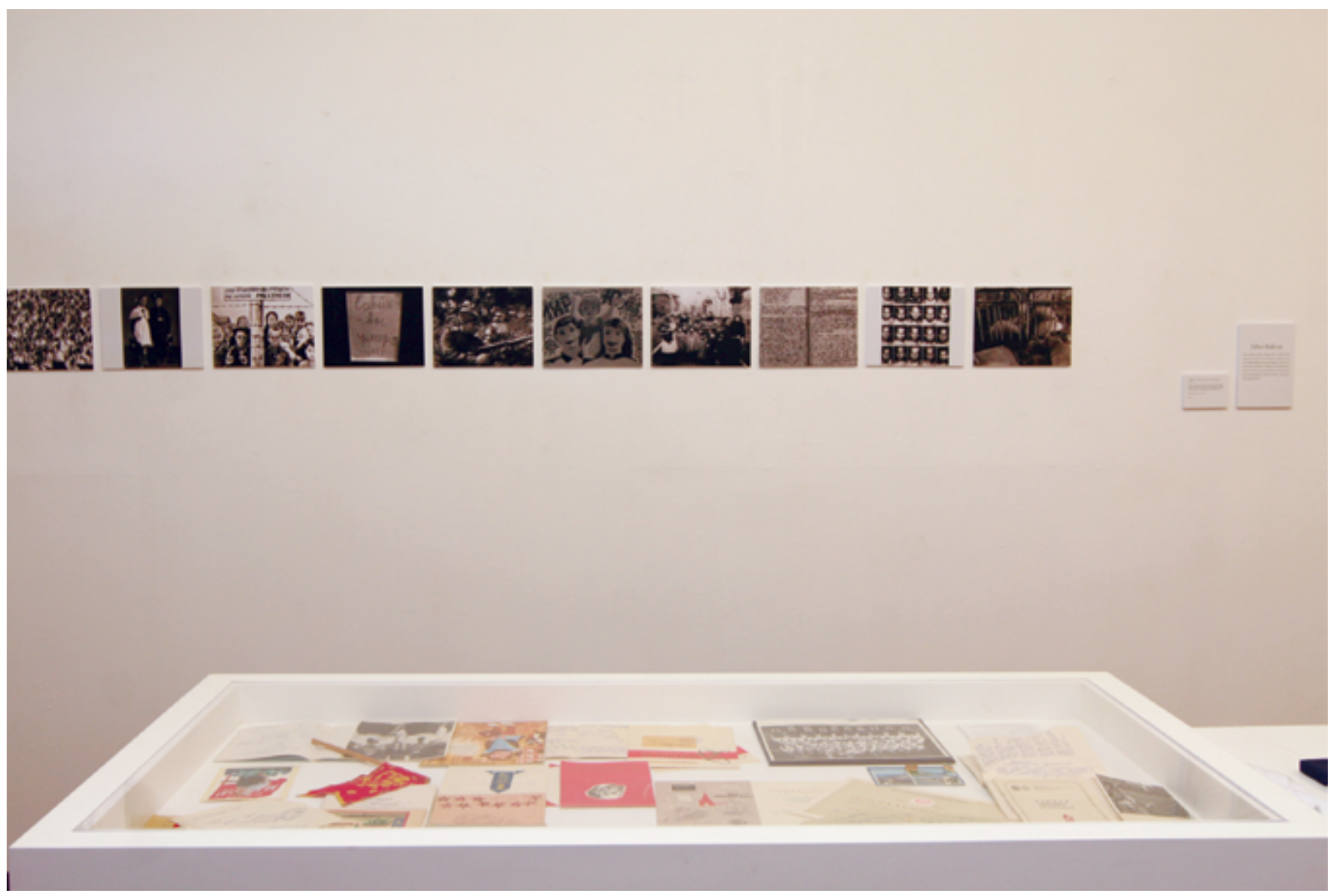

FIGURA 4. Imágenes de apoyo museográfico en el núcleo "Muerte y pacifismo", fechas varias. Fotografías, reconocimientos y cuadernos del primer año de primaria de loulia Akhmadeeva, 1978 (Fotografía: Alternativa Gráfica, 2015; cortesía: Ioulia Akhmadeeva). 
longación y fin, la estancia en el hospital, el enterarse de la muerte de su madre y amigos, para concluir: "La memoria es sorprendente: siempre trata de borrar lo peor, lo más espantoso, doloroso" (Agunda Bataeva 2004, en Akhmadeeva 2015:56, 79, 80).

\section{Violencia y educación formal}

loulia Akhmadeeva indaga sobre la relación entre violencia y la educación formal estatalmente activada con imaginería del armamentismo como signo de progreso, muy en boga durante su infancia en la Unión de Repúblicas Socialistas Soviéticas (URSS). Esto lo hace en dos libros de artista que puso en diálogo con la información documental audiovisual de procesos violentos en México y el mundo, descrita en el apartado anterior.

El primero es Bukvar (Akhmadeeva 2014-2015), intervención de una reproducción facsimilar del libro con el que aprendió a leer, un texto de primaria de la URSS de 1978. Akhmadeeva insertó aleatoriamente en ese facsimilar imágenes impresas en acetatos con temas de violencia o de personajes públicos alentando una causa, o militantes armados defendiéndola o acoplándose a un patrón de disciplina de manejo de masas sociales. Unos guantes junto a la pieza invitaban a completarla apreciándola como espectadores activos al manipularla con ellos puestos, hojear el libro y armar propias tramas de significación, en contraposición con las imágenes bucólicas y pintorescas que acompañaban palabras en tipografía de gran formato y la imaginería implacable de los acetatos. ¿Puede el mundo que reproduce el libro de lectura resistir los embates de registros visuales de procesos de conflicto?

Este libro se colocó, junto a la vitrina de fotografías, con reconocimientos y cuadernos del primer año de educación básica pertenecientes a la artista, con lo que se documentó una infancia dentro de parámetros normales de vida social y escolar. Bukvar cuestiona todo esto en la brusca mezcla visual entre las páginas del libro reproducido y las imágenes violentas insertas en acetato (Figuras 5 y 6 ).

Un recurso de aprehensión de diversas construcciones de sentido en esta pieza son las frases o palabras sobre este proyecto de los estudiantes entrevistados: "Pérdida de la inocencia a partir de la guerra", "Infancia intervenida", "recuerdo las flores entre las armas" (García 2016; Mojica 2016; Rodríguez 2016: comunicaciones personales).

El segundo volumen, Libro híbrido (Akhmadeeva 2014-2015), combina conflictos territoriales étnicos con la procedencia e historia de la familia paterna de Akhmadeeva, en una intención, que explicó en nuestras sesiones de trabajo, de cuestionar la idealización del armamentismo, boyante en la URSS de la infancia de la creadora (Akhmadeeva 2015: comunicación personal). Dicha idealización queda documentada y en diálogo con este proyecto, al convivir espacialmente con los materiales de su infancia en vitrina; sobre todo del campamen-
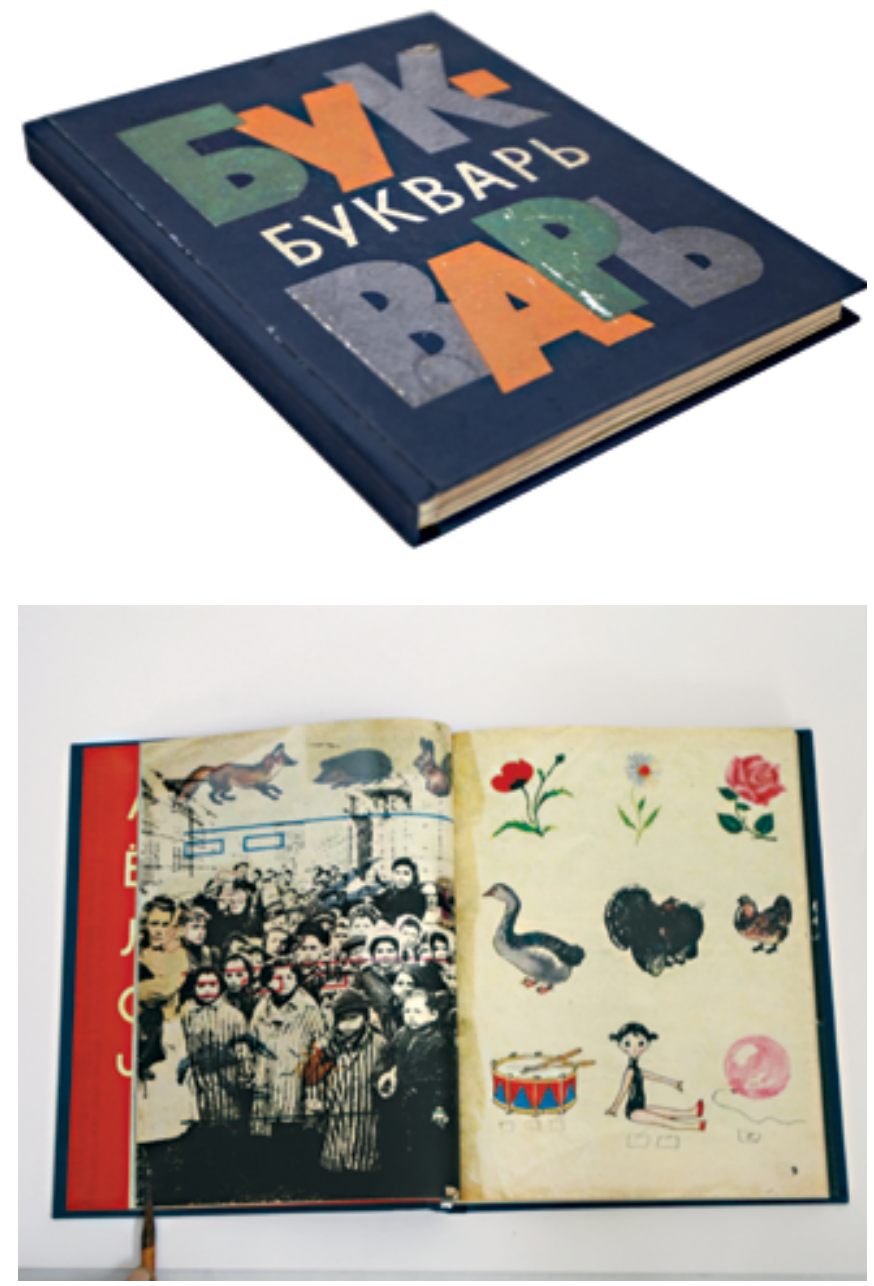

FIGURAS 5 y 6. Bukvar. Ensayo de una protesta. Libro-arte. Facsímil del primer libro de texto de primaria de loulia Akhmadeeva en 1978 en DDR y URSS, con inserciones de impresiones láser en acetato de imágenes de dominio público. Encuadernación: Alternativa Gráfica, 2015 (Fotografía: Alternativa Gráfica, 2015; cortesía: Ioulia Akhmadeeva).

to internacional "Artek" en Crimea, hoy, en la guerra de Donbass (Figuras 7 y 8 ).

Imágenes a lo largo del libro, con combinaciones de armas y flores y el uso simbólico del rojo en sus tapas y el dorado "celestial" (así califica la autora, irónicamente, este color) en las guardas, junto con tejidos, transferencias en papel artesanal de avena y aplicaciones de hoja de oro, albergan el pasado intercultural familiar de la autora, conformado por rusos, ucranianos y tártaros, y su presente híbrido, precisamente, con la crianza de su familia en México (Akhmadeeva 2015:45).

Esta pieza se exhibió apoyada sobre un mapa de Rusia. Una de las puntas de la encuadernación coincidía, justamente, con la zona de Crimea. Las frases o palabras solicitadas a los estudiantes entrevistados en la pregunta 2 del guion de la entrevista (cfr. apartado introductorio de este ENSAYO) permiten ampliar las líneas de recepción del proyecto: "Violencia y sangre derramada", "sacralidad y violencia", "apunta más a loulia, es su pueblo, su ciu- 

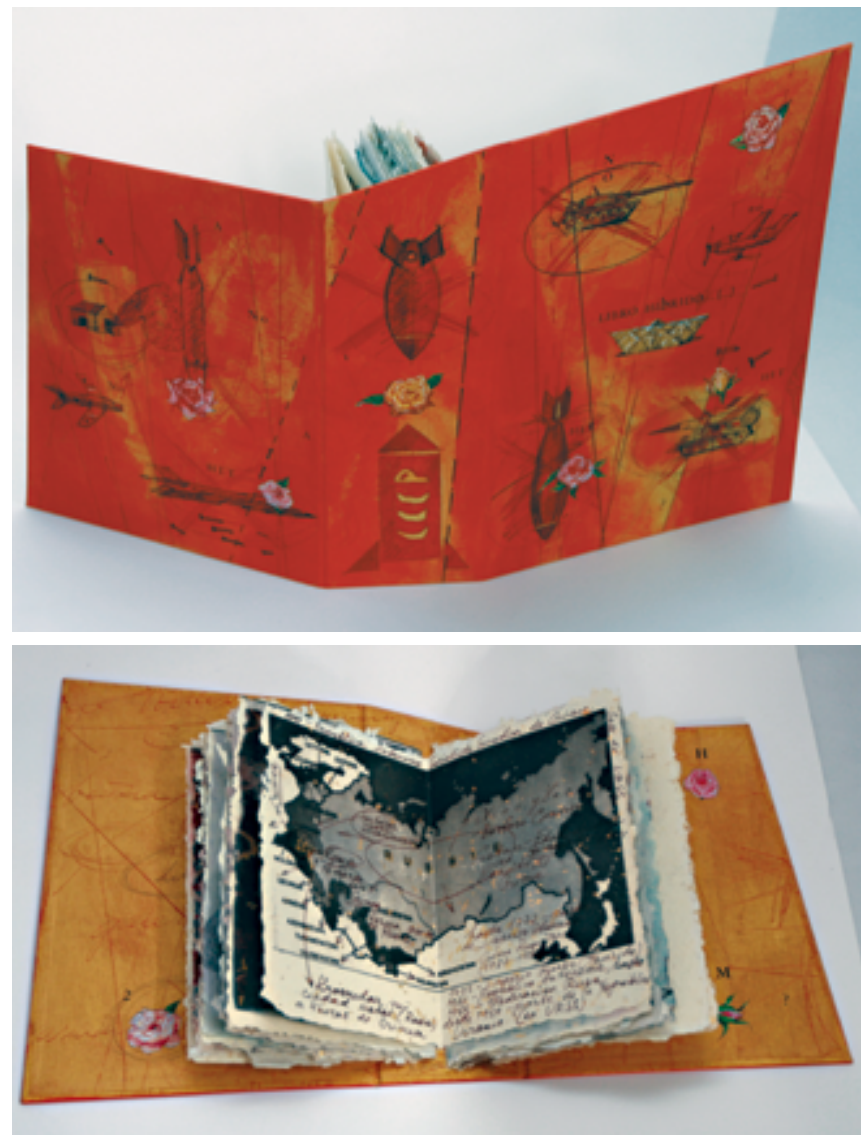

FIGURAS 7 y 8 . Libro híbrido. Libro-arte. Pastas intervenidas con acrílico y calcomanías. Transferencia electrográfica en papel hecho a mano con fibra de avena y hoja de oro, 2014-2015 (Fotografía: Alternativa Gráfica, 2015; cortesía: Ioulia Akhmadeeva).

dad" (García 2016; Mojica 2016; Rodríguez 2016: comunicaciones personales). Estas respuestas, así como las notas asentadas en la libreta de comentarios de la exposición (2016), apuntan hacia otra vertiente de análisis, que es la de la mirada del público. Ambas fuentes, que documentan procesos de percepción de los espectadores en esta muestra de Akhmadeeva, dejan ver que los testimonios específicos sobre "Muerte y pacifismo" fueron empáticos con la denuncia y la reflexión sobre la violencia en el mundo actual. Las apreciaciones de las personas se vincularon con la desazón que la propia Akhmadeeva (2015: comunicación personal) quería transmitir, como postuló en las sesiones de trabajo durante la preparación de la exposición.

\section{Investigación iconográfica y prácticas artísticas para reflexionar masacres y forzamiento de trabajos, exilios y desapariciones}

El libro-instalación Día de conocimiento (Akhmadeeva 2015) era el elemento más importante del núcleo "Muerte y pacifismo"; se lo podía percibir a lo lejos al llegar a esta zona, y luego, una vez que se la recorría, no sin antes observar los demás proyectos y los materiales de archivo, se apreciaba de cerca y en detalle.
Por su ubicación en sala, en Día de conocimiento aparecía a la percepción, en el sentido plenamente fenomenológico, aquello que para Husserl (1992 [1927]) emergía a nuestra conciencia, o nuestro darnos cuenta de que algo está frente a nosotros, incidiendo en lo significativo de nuestra percepción. En mi opinión, este libro-instalación "nos vigila" al fondo del núcleo y durante el recorrido: particular fuerza visual tienen las piedras trastocadas, por estar suspendidas en el aire (un elemento pesado y denso, flotante) alrededor del tradicional delantal que usaba Ioulia Akhmadeeva en su infancia y que llevaban las niñas rusas en el Día de conocimiento, que, como mencioné antes, ocurría cada 1 de septiembre en Rusia (Akhmadeeva 2015: comunicación personal), y que aquí se presenta impreso con piedras, como si tales terminaran finalmente estrelladas y embebidas en esa prenda de vestir, invadida, a su vez, por las rocas. Esto alude a algo efectivamente sucedido en la masacre en la primaria de Beslán: luego de que el 1 de septiembre los militantes suicidas islámicos chechenos e ingusetios que reivindicaban la desocupación rusa de Chechenia sitiaron la escuela, el 3 de septiembre reforzaron el ataque armado, de acuerdo con lo que relata Akhmadeeva (2015: comunicación personal), lanzando piedras hacia los rehenes.

Al mismo tiempo, del delantal "brotaban" hacia el piso impresiones en forma de hojas de árbol, en referencia a la estación otoñal en que se festeja el Día de conocimiento en las escuelas rusas. Lo impreso en cada hoja es un rostro de un niño o un joven muerto en Beslán, Rusia, o en Guerrero, México, en la mezcla libre de alusiones a sucesos violentos que hizo Akhmadeeva en ese núcleo de la exposición (2015); también se imprimió en algunas de estas hojas el rostro de Gilberto Abundiz. Las hojas tenían al reverso el nombre de la persona. En el suelo había un montículo, como del tipo de vistas que forman las hojas caídas otoñales, y, alrededor de él, vasos con agua: "un calmar la sed" póstumo, ya que, como relató Akhmadeeva (2015: comunicación personal), uno de los rasgos del sitio de Beslán fue no dejar que los rehenes tomaran agua (Figuras 9 y 10).

Las frases o palabras recopiladas de dos de los estudiantes entrevistados se intersecan con vínculos y visibilidades que las personas pueden establecer con este libro-instalación: "Niños como hojas de otoño", "Es como revelar toda una identidad anónima. Estás viendo a todas estas personitas en las hojas, tú no sabes nada, hasta que te enteras [de] que son víctimas de X o Y tragedia" (García 2016; Rodríguez 2016: comunicaciones personales).

$\mathrm{Y}$ hay en este libro-instalación otro manejo de lo archivístico, señalado en el análisis reciente de Hal Foster (2015:38-40) del arte-archivo respecto del potencial comunicativo de las resoluciones visuales o plásticas en las piezas donde se recuperan materiales de este tipo: una producción objetual o tridimensional a modo de altarquiosco que, por sus rasgos, detona un sentido devocional $y$, al mismo tiempo, informativo que potencializa un uso político de la emotividad y la afectividad artística 


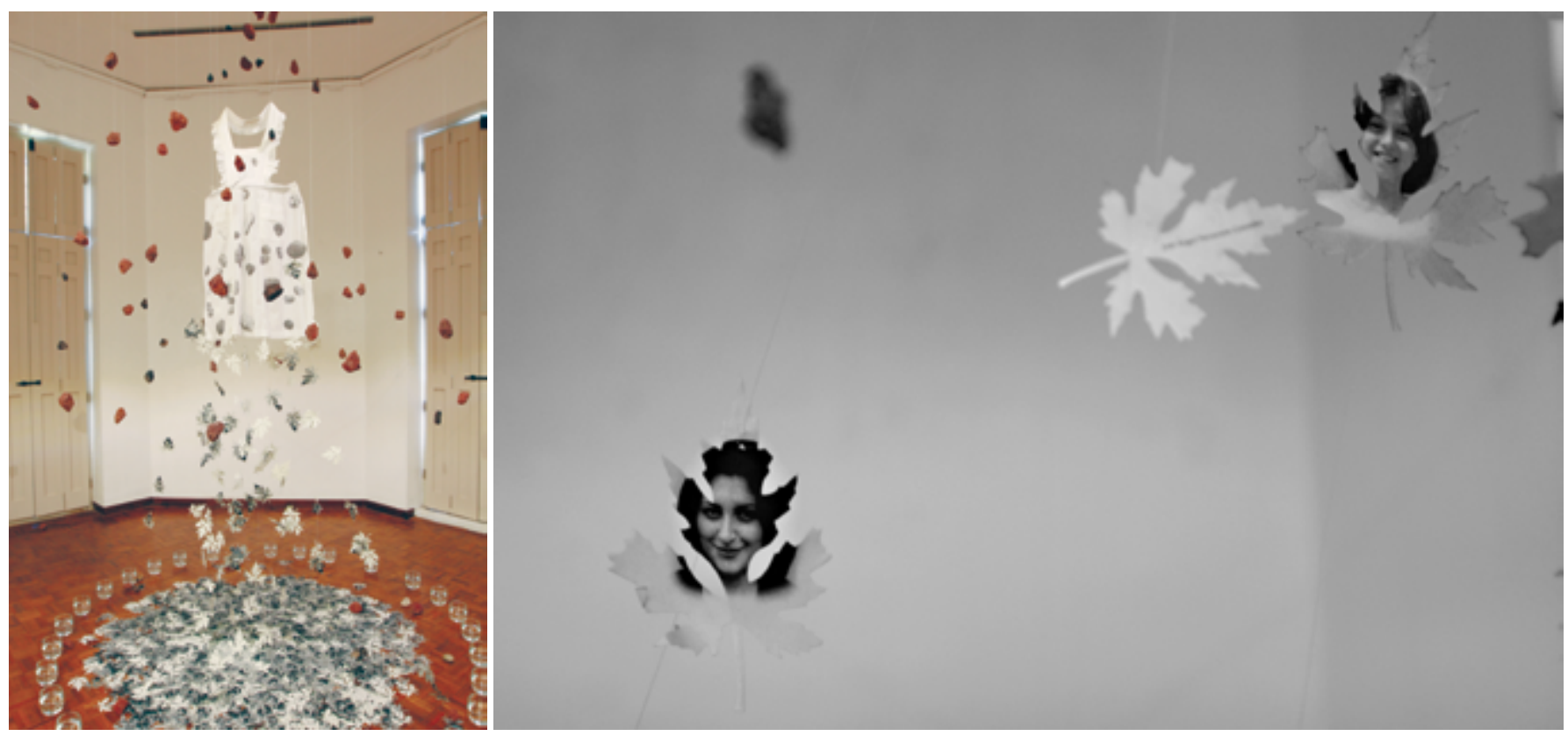

FIGURAS 9 y 10. Día de Conocimiento. Libro-instalación. Mandil blanco del uniforme escolar de loulia Akhmadeeva, intervenido con impresiones en transferencia electrográfica, piedras volcánicas de dimensiones diversas, hilos de nylon, 4000 hojas de plantas en papel con impresión digital de rostros y nombres de víctimas de las masacres de Ayotzinapa y Chilapa en Guerrero, México, y de Beslán, Osetia, Rusia, 30 recipientes de vidrio con agua, 2015 (Fotografía: Alternativa Gráfica, 2015; cortesía: loulia Akhmadeeva).

que ya había postulado en su momento Walter Benjamin (1973 [1936]:31-48) en la interacción entre el aura, energía irradiante del aquí y ahora de las piezas, y sus valores cultuales y de exhibición.

Reflexiones finales: significación expandida del archivo en las piezas de loulia Akhmadeeva, su recepción en Michoacán e historia reciente

En el núcleo "Muerte y pacifismo" de la exposición Desde y para la memoria de loulia Akhmadeeva, el archivo expande su significación al ponerlo en interacción con piezas artísticas, o por formar parte de ellas, como contrapunto documental de la experiencia sensible. No sólo eso: el carácter polisémico del libro de artista, como la principal práctica creativa que Akhmadeeva articula a lo largo de la muestra, ocurre a través de engarzamientos de experiencias al ir y venir entre cada proyecto. Esto pudiera guardar semejanza con un proceso similar al pensamiento complejo analizado por Deleuze (2015 [1977]), y explicarlo como la incidencia simultánea y recíproca de diversos sucesos vitales que generan en los sujetos eslabones de significación sin subordinaciones entre sí. O, dicho en términos de Barthes (1987 [1970]:84-85), "vacilaciones de los signos/fisuras en la representación".

En la exposición sucede, por asociaciones discursivas en una especie de intercambio de roles, cierta agencia de condición artística del archivo, debida, asimismo, a su presencia latente en el espacio expositivo y a una voluntad testimonial y visibilizadora de problemáticas en las piezas de la artista. La cultura visual y material funciona también con base en estas expansiones de sentido entre un ir y venir entre vida cotidiana y significación en producciones culturales diversas (Dikovitskaya 2005:4784), como, en este caso, donde repertorios sonoros, visuales, audiovisuales y escolares constituyen un bagaje documental que, sujetos a una contemplación sensible, pueden figurar de un modo interpretativo ante la percepción del espectador, en la firme intención artística y curatorial de esta muestra de desarrollar la violencia como tema en el espacio del museo, usando la curaduría como herramienta reflexiva crítica, inscribiéndose este núcleo de la exposición: "Muerte y pacifismo", de Akhmadeeva, en otros casos al interior de museos - como el Museum of Modern Art (MOMA, Museo de Arte Moderno), en Nueva York, por ejemplo- que han realizado proyectos con esta tendencia (Antonelli 2016).

Los testimonios de los estudiantes entrevistados aluden a estos procesos. Por un lado, hay una recurrencia en señalar el contraste entre el paisaje sonoro o el repertorio musical alegre de fondo del documental audiovisual y las imágenes violentas que lo poblaban (cfr. García 2016; Mojica 2016; Rodríguez 2016: comunicaciones personales), y, por el otro, la fuerza de realidad que anclaba la percepción en los materiales de archivo complementando o integrando las piezas, como muestra el siguiente testimonio: "porque una pieza puede pedir justicia o mostrar lo que el artista quiere denotar, pero [...] el material de archivo te daba cuenta de que esto fue real y justamente eso lo convierte en algo que te pudo haber pasado a ti" (García 2016: comunicación personal).

Vale la pena confrontar estas visiones con una reflexión personal. Es frecuente que grupos de comunidades colindantes con la autopista federal núm. 200 entre 
las ciudades de Morelia y, en la costa del océano Pacífico, Lázaro Cárdenas, Michoacán, bloqueen las casetas de cobro para reivindicar distintas causas políticas y socioeconómicas (cfr. García Tinoco 2017). En el 2014, al trasladarme de Morelia a la costa del estado de Guerrero por el área de Tierra Caliente perteneciente a Michoacán durante la pausa vacacional de Semana Santa, sucedió esto en la caseta de la ciudad de Uruapan: si uno quería continuar hacia la costa michoacana, debía tomar las pequeñas carreteras internas que cruzaban localidades como Cuatro Caminos, Apatzingán, Nueva Italia, Lombardía, hasta entroncarse nuevamente con la autopista hacia Lázaro Cárdenas. Todas estas localidades tienen visibilidad reciente por el surgimiento de las autodefensas, o grupos locales civiles, que realizaban actividades paramilitares para protegerse de las coerciones de los grupos del crimen organizado en sus comunidades (Rivera 2013). Al cruzarlas, me topé con huellas de enfrentamientos: restos de barricadas con llantas y costales con materiales, retenes de autodefensas. Impresionaba que los jóvenes que los custodiaban portaban armas de calibre grueso a plena luz del día en áreas con alto flujo de vehículos. Daban información sobre rutas para volver a tomar la autopista, pero yo no dejaba de pensar en lo que pasaría con todos los civiles que circulábamos por ahí si de pronto se diera un enfrentamiento entre ellos y algunos miembros del crimen organizado que circularan en un vehículo.

En contraste, en la ciudad de Morelia y las poblaciones en los alrededores del lago de Pátzcuaro, parece existir un relativo estado de "pacto de seguridad" que hace que no haya sucesos tan dramáticos como el atentado del crimen organizado en el 2008 durante los festejos de la Independencia de México, en la noche del 15 al 16 de septiembre, en una plaza pública ubicada a un lado de la Catedral de Morelia, con detonación de granadas, en el que las cifras oficiales fueron de menos de 10 muertos y más de 100 heridos, atribuido, en un principio, al cártel Ilamado Familia Michoacana, después a la agrupación Los Zetas y al grupo guerrillero Ejército Popular Revolucionario (EPR). Todas estas organizaciones se deslindaron del atentado (cfr. Rivera 2008).

Asimismo, en localidades alrededor del lago de Pátzcuaro ha habido migraciones recientes de familias de Tierra Caliente vinculadas con el crimen organizado que alteran dinámicas sociales anteriores a su llegada (Grupo Reapropiación del Espacio Público en Erongarícuaro 2014-2015). ${ }^{1}$

De acuerdo con los reportajes de Rivera (2013), Calderón (2015) y Quesada (2015), en la zona de Tierra Calien-

\footnotetext{
${ }^{1}$ En testimonios de conversaciones informales con jóvenes integrantes de este grupo, habitantes de la cabecera municipal de Erongarícuaro, noviembre del 2014-enero del 2015, hablan del establecimiento de la práctica frecuente del crimen organizado de cobrar derecho de piso a los negocios locales, operación que ocurre en las comunidades a las que llegan, más vandalismo de los jóvenes de esas familias.
}

te al menos desde el 2013 existían grupos de autodefensas como una medida social autogestiva ante la corrupción de las autoridades estatales que protegen a grupos delicuenciales, particularmente en ese momento, al cártel Los Caballeros Templarios. Las investigaciones de los autores citados establecen que los enfrentamientos de las autodefensas y la negociación gubernamental con estos grupos de la sociedad civil desembocaron en el 2014 con la disolución de los últimos y el apresamiento de algunos de sus líderes, como Hipólito Mora (actualmente libre, cuyo hijo murió en un tiroteo) y el doctor Mireles, recientemente liberado con graves problemas de salud (CasteIlanos 2017). En el 2015 este proceso se caracterizó por la militancia política por canales oficiales de antiguos elementos de autodefensas, como el mismo Mora.

También fracasaron las políticas de desarme en la entidad, y continuaron los enfrentamientos armados, como dejó ver el tiroteo en Tanhuato, municipio ubicado en la colindancia entre los estados de Michoacán y Jalisco, en el que hubo más de 40 muertos (Calderón 2015; Quesada 2015). En mi opinión, luego de tres años de vivir y trabajar en la ciudad de Morelia, estos procesos de violencia han contribuido a la actual crisis económica, al desempleo y a la depresión de actividades económicas en el estado, así como a la corrupción en el manejo de los presupuestos locales y el clientelismo político.

Llama la atención que los estudiantes entrevistados se refirieron a conflictos en los estados de Michoacán y de México, con lo que dejaron ver un enfoque de sus resonancias con las problemáticas históricas y sociopolíticas que loulia Akhmadeeva manejó en "Muerte y pacifismo", como queda ejemplificado en el siguiente testimonio:

Estudiante 3: aquí en Michoacán ha estado pasando una fuerte situación de matanzas, de amenazas, y tal vez se vivan de una manera muy distinta, pero siguen siendo lo mismo, violencia, [...] aunque uno esté tranquilo, normal, se queda en tu mente [...]. Cuando de pronto se vuelve tan normal ver que matan a alguien [...] las cosas ya avanzaron mucho [...] la exposición te hace sentirte cercano a esos hechos (García 2016: comunicación personal).

Hay un ineludible balanceo entre los procesos históricos aludidos por loulia Akhmadeeva en el área expositiva que revisa procesos de violencia y sucesos de las realidades inmediatas de los espectadores: la libreta de comentarios también arrojó testimonios elocuentes en este sentido, como, por ejemplo, el siguiente: "De pronto un viaje. Los pasos de otros han sido siempre nuestros pasos y sus risas y su sangre" (Anón. 2015).

En mayo del 2016 hubo la oportunidad de reflexionar sobre este caso expositivo durante la realización del taller Visualidades desplazadas. Archivos, amnesia y prácticas estéticas más allá del lugar común, en el Center for Latin American and Caribbean Studies (CLACS, Centro de Estudios Latinoamericanos y del Caribe) de la New York Uni- 
versity (NYU, Universidad de Nueva York), Estados Unidos, previo al XXXIV Congreso de la Latin American Studies Association (LASA, Asociación de Estudios Latinoamericanos), organizado por su sección de Cultura Visual.

La reflexión colectiva generó líneas de investigación a partir de la exposición de loulia Akhmadeeva sobre la responsabilidad comunicativa de procesos que conjuntan temas de archivo, creación y violencia, y su divulgación expositiva (Barriendos-Rodríguez et al. 2016):

La revisión permanente entre quienes participan como artistas, curadores y gestores de proyectos sobre cómo se habla de la violencia en estas iniciativas se postuló como premisa inicial para resignificar violaciones a derechos humanos, haciendo conciencia acerca de la manera de actuar para que no se repitan. Esto debe darse en el marco de una socialización en las comunidades inmediatas de los proyectos referidos, de modo que éstas también aporten ideas para la visibilidad del repudio a los atropellos sociopolíticos a escala mundial, pero que también denuncien si los proyectos se exceden y, más que fortalecer, atrofian la sensibilidad social sobre estos temas, y en qué medida es fructífero o no el uso creativo de imágenes de archivo sobre los sucesos históricos que se quieren enfatizar.

En este sentido, la distancia crítica entre curador y artista es indispensable como principio que seleccione y calibre los contenidos para evitar normalizar lo violento por exceso de visibilidad.

En el caso específico de la exposición de loulia Akhmadeeva, el uso creativo que le dio a materiales de archivo de hechos en diversas partes del mundo se inscribe en el fenómeno actual de circulación mundial de información de sucesos violentos que, al documentarse, hace que las imágenes de archivo adquieran un carácter itinerante y móvil, frecuentemente con una función incómoda por la mezcla de diferentes acontecimientos y contextos, y por razón de que problematizan cuestiones como la activación política de procesos de memoria, debates sobre si lo legislado es justicia (es decir, si las leyes representan las necesidades y los derechos sociales históricos de los diversos grupos culturales que habitan un país), si ésta se consigue sólo de modo transicional y en qué medida iniciativas creativas, como la que comento, se insertan en dinámicas de resistencia o de reconciliación entre el presente y el pasado.

Para "Muerte y pacifismo" y la obra de Akhmadeeva en ese núcleo de su exposición, se verifican planteamientos analíticos de Hal Foster (2015:59-60) en torno del "arte archivístico": la intención de conectar información de sucesos que en principio parecieran imposibles de relacionar, para reelaborar nuevas sendas de un pasado que implican al presente, lo que genera un impulso alegórico basado en lo archivístico y en su tratamiento fragmentario, integrado por anomias y disturbios internos en el espectador que, más que juzgarse, debieran ser condiciones que posibilitan nuevos órdenes de asociaciones afectivas que abandonan el estado en pausa en que suele estar un archivo para transformarlo en un estado de posibilidad de transformación social, un sitio de construcción por la reflexión, detonados por los vestigios que alberga, y no sólo de excavación extractiva de datos.

Después de este análisis del proceso expositivo, discursivo y curatorial de "Muerte y pacifismo", un argumento final que aventuro en relación con las preguntas de inicio de este texto es que la expansión de disciplinas plásticas experimentada en esta muestra sí es un agente que impulsa la conciencia social. El caso aquí tratado y las evidencias de recepción pública de la exhibición dejan ver cómo el asombro sensible que generó en las personas el material de archivo, lo documental y procesos de investigación iconográfica, planteados como materia artística expresiva, sí contribuyen a fortalecer posicionamientos políticos en ellas.

Otro eje que activa las preguntas iniciales de este escrito en cuanto a lo experimental en gráfica manejada tridimensionalmente es una indagación particular y persistente en loulia Akhmadeeva: ¿en qué medida la educación formal puede convertirse en un agente de circulación de mensajes violentos?, y la artista aporta los planteamientos de prueba desde el manejo expresivo de su propio archivo personal, los cuales enfatizan los rasgos de sus materiales con imaginarios de violencia que difunde el propio sistema escolar.

Al inquirir sobre la contribución de la reflexión museológica para visibilizar estos mecanismos de posicionamiento político y de crítica a las deformaciones educativas en una exposición en museo, la resolución es tan indeterminada como los alcances comunicativos de las exhibiciones en los públicos. Cada espectador activa su mundo propio en la acogida con que acomete los estímulos de los dispositivos de una muestra. Reflexionar sobre esto, así como que las resoluciones sean inexorables, no debiera minimizar la riqueza epistemológica del andar en sí el camino explorado en este tipo de indagaciones cualitativas.

\section{Agradecimientos}

Ioulia Akhmadeeva, Alternativa Gráfica, Joaquín Barriendos-Rodríguez, Lisa Blackmore, Kevin Coleman, Sección de Cultura Visual del XXXIV Congreso de la Latin American Studies Association (LASA, Asociación de Estudios Latinoamericanos), Escuela Nacional de Estudios Superiores (ENES)-Unidad Morelia, de la Universidad Nacional Autónoma de México (UNAM), Alison Fraunhar, Alexis Salas, Alex Schlenker y Gabriela Zamorano.

\section{Referencias}

\section{Akhmadeeva, loulia}

2015 Comunicación personal. Sesiones de trabajo en el taller de la artista, Morelia, mayo-octubre. 
2015 Desde y para la memoria. Ioulia Akhmadeeva, catálogo de exposición, Morelia, Universidad Michoacana de San Nicolás de Hidalgo (UMSNH).

2015-2017 Biografía, documento electrónico [página web] disponible en [http://www.ioulia-akhmadeeva.net], consultado en mayo de 2017.

Anón.

2015 "Libreta de comentarios a la exposición Desde y para la memoria. Ioulia Akhmadeeva", documento manuscrito inédito, Morelia, Museo de Arte Contemporáneo "Alfredo Zalce", (Macaz)/Secretaría de Cultura del Estado de Michoacán.

Antonelli, Paola

2016 "Design and Violence as Open Curatorial Experiment at the Science Gallery Dublin, Ireland", The Museum of Modern Art (MOMA), documento electrónico disponible en [http://de signandviolence.moma.org/archives/?order=ASC\&sort=title], consultado en mayo de 2017.

Barriendos-Rodríguez, Joaquin, L. Blackmore, K. Coleman et al. 2016 "Archives revisited: from raw footage to creative montage", panel en el taller grupal oral Dis/placed Visualities. Archives, Amnesia and Aesthetic Practices beyond the Commonplace, actividad previa al XXXIV Congreso LASA (Latin American Studies Association), Nueva York, Center for Latin American and Caribbean Studies-New York University (CLACS-NYU).

Barthes, Roland

1987 [1970] "La mitología hoy", en R. Barthes, El susurro del lenguaje. Más allá de la palabra y la escritura, Barcelona, Paidós.

Benjamin, Walter

1973 [1936] "La obra de arte en la época de su reproductibilidad técnica", en Discursos Interrumpidos I, Madrid, Taurus.

Calderón, Verónica

2015 "La estrecha relación entre la política y el narco en Michoacán", El País, Autodefensas michoacanas, documento electrónico [página web] disponible en [http://elpais.com/ tag/autodefensas_mexicanas/a], consultado en marzo de 2016.

Castellanos, Francisco

2017 “Liberación de Mireles evidencia que el gobierno actuó de manera selectiva: Leonel Godoy", Proceso, 12 de mayo, documento electrónico disponible en [http://www.proceso. com.mx/486309/liberacion-mireles-evidencia-gobierno-actuo-manera-selectiva-leonel-godoy], consultado en mayo de 2017.

Colas, Xavier

2015 "Putin admite que tuvo a combatientes luchando en el este de Ucrania", El Mundo, 17 de diciembre, documento electrónico disponible en [http://www.elmundo.es/internacio nal/2015/12/17/56729bf422601d2a3f8b464b.html], consultado en marzo del 2016.

Conquest, Robert

1997 "Victims of Stalinism: A Comment", Europe-Asia Studies, 7 (49):1317-1319, documento electrónico disponible en [http:// sovietinfo.tripod.com/CNQ-Victims_Stalinism.pdf], consultado en marzo de 2016.
Corona, Sergio René de Dios

2014 "Ayotzinapa es México", en Luis José Guerrero Anaya, Luis Marrufo Cardín y Juan Carlos Núñez Bustillos (eds.), Análisis Plural. Los 43 que marcan a México, Guadalajara, Instituto Tecnológico y de Estudios Superiores de Occidente (ITESO)-Universidad Jesuita de Guadalajara, 85-98, documento electrónico disponible en [http://cfh.iteso.mx/documents/11309/0/Analisis_Plural_2S2014.pdf/b9d822f0-df78450f-a85c-1d0355989789], consultado en marzo de 2016.

Deleuze, Gilles

2015 [1977] "Introducción", Rizoma, documento electrónico disponible en [http://www.fen-om.com/spanishtheory/theory104. pdf], consultado en septiembre de 2015.

Dikovitskaya, Margarita

2005 Visual Culture. The Study of the Visual after the Cultural Turn, Londres/Cambridge (EE. UU.), MIT Press.

Duranti, Alessandro

2000 Antropológica Lingüística, Madrid, Cambridge University Press.

Foley, William

1997 Anthropological Linguistics. An Introduction, Oxford, Blackwell Publishers.

Foster, Hal

2015 "Archival", en Bad New Days. Art, Criticism, Emergency, Londres/Nueva York, Verso Books, 31-60.

García, Luis Fernando

2016 Comunicación personal, entrevista realizada en el Laboratorio de Historia del Arte, Escuela Nacional de Estudios Superiores-Unidad Morelia-Universidad Nacional Autónoma de México (ENES-UNAM), Morelia, febrero.

García Tinoco, Miguel

2017 "Suspenden corridas de autobuses en Morelia por bloqueos", Excélsior, 18 de mayo, documento electrónico disponible en [http://www.excelsior.com.mx/nacional/2017/ 05/18/1164338], consultado en mayo de 2017.

Goffman, Erwin

1983 Forms of Talk, Filadelfia, University of Pennsylvania Press.

Grupo Reapropiación del Espacio Público en Erongarícuaro 2014-2015 Conversaciones informales con jóvenes habitantes de la cabecera municipal de Erongarícuaro, Michoacán.

Hernández, Francisca

2007 "La museología ante los retos del siglo XXI", Revista de Patrimonio e-rph (1) 1:4-26, documento electrónico disponible en [https://dialnet.unirioja.es/descarga/articulo/4013092. pdf], consultado en enero de 2017.

Husserl, Edmund

1992 [1927] "Fenomenología", Enciclopedia Británica, Invitación a la fenomenología, Barcelona, Paidós, documento electrónico disponible en [http://www.posgrado.unam.mx/ musica/lecturas/LecturalntroduccionInvestigacionMusical/ epistemologia/Husserl\%20El-Articulo-Fenomenologia-deLa-Enciclopedia-Britanica.pdf], consultado en mayo de 2017. Jewish Virtual Library

s.f. "Concentration Camps: full listing of camps", Jewish Virtual Library, documento electrónico [página web] disponible 
en [http://www.jewishvirtuallibrary.org/jsource/Holocaust/ cclist.html], consultado en marzo de 2016.

McAllister, J. F. O. y Paul Quinn-Judg

2004 "The whole world is crying. Beslan", Time,12 de septiembre, documento electrónico disponible en[http://content. time.com/time/magazine/article/0,9171,901040920-695815, 00. html], consultado en marzo de 2016.

Mojica, Iris

2016 Comunicación personal, entrevista realizada en el Laboratorio de Historia del Arte-Escuela Nacional de Estudios Superiores-Unidad Morelia-Universidad Nacional Autónoma de México (ENES-UNAM), febrero.

Ochs, Elinor y Bambi Schieffelin

1997 "The microgenesis of competence: methodology in language socialization", en Dan Slobin et al. (eds.), Social Interaction, Social Context, and Language, Nueva Jersey, Lawrence Erlbaum Associates, 251-260.

Paton Walsh, Nick y Peter Beaumont

2004 "When hell came calling at Beslan's School No. 1", The Guardian, 5 de septiembre, documento electrónico disponible en [http://www.theguardian.com/world/2004/sep/05/russia.chechnya], consultado en marzo de 2016.

Pigeonutt, Vania

2015 "Hallan cuerpo de desaparecido en Chilapa", El Universal, 28 de mayo, documento electrónico disponible en [http://archivo.eluniversal.com.mx/estados/2015/hallancuerpo-de-desaparecido-en-chilapa-1103218.html], consultado en marzo de 2016.

Quesada, Juan Diego

2015 "Hipólito Mora, el candidato que acaricia la escopeta", El País. Autodefensas michoacanas, documento electrónico [página web] disponible en [http://elpais.com/tag/au todefensas_mexicanas/a/], consultado en marzo de 2016.

Redacción BBC Mundo

2015 "Los países que verdaderamente cargan con el peso de la migración siria", BBC Mundo, 10 de septiembre, documento electrónico disponible en [http://www.bbc.com/ mundo/noticias/2015/09/150909_internacional_vecinos_siria_numeros_conflicto_interno_amv], consultado en marzo de 2016.

Rivera, Rafael

2008, "Atentados en Morelia: registran otra explosión", El Universal, 16 de septiembre, documento electrónico disponible en [http://archivo.eluniversal.com.mx/notas/538669. html], consultado en marzo de 2016.
Rivera Velázquez, Jaime

2013 "El abismo michoacano", Nexos, 1 de septiembre, documento electrónico disponible en [http://www.nexos.com. $\mathrm{mx} / \mathrm{p}=15462$ ], consultado en mayo de 2017.

Rodríguez, Diego 2016 Comunicación personal, entrevista realizada en el Laboratorio de Historia del Arte-Escuela Nacional de Estudios Superiores Unidad Morelia-Universidad Nacional Autónoma de México (eneS-UnAM), febrero.

Sánchez Herráez, Pedro

2015 “La pugna por el espacio postsoviético. La cuestión de las minorías rusas", Panorama geopolítico de los conflictos, documento electrónico disponible en [http://www.ieee.es/ Galerias/fichero/panoramas/Panorama_Geopolitico_Conflictos_2015.pdf], consultado en marzo de 2016.

Zetter, Roger y Héloïse Ruaudel

2014 "Los desafíos de desarrollo y protección de la crisis de refugiados sirio", Migraciones Forzadas, 47:39-40, documento electrónico disponible en [http://www.fmreview.org/sites/ fmr/files/FMRdownloads/es/siria/RMF47_siria.pdf], consultado en marzo de 2016.

\section{Síntesis curricular del/los autor/es}

\section{Eugenia Macías Guzmán}

Museo Morelense de Arte Contemporáneo (MMAC) "Juan Soriano" eugenia.macias@gmail.com

Maestra en antropología social (Centro de Investigaciones y Estudios de Antropología Social [CIESAS]) y doctora en historia del arte (Universidad Nacional Autónoma de México [UNAM]). Ha fungido como catalogadora y curadora en la Fundación Televisa, el Museo de Arte Moderno (MAM), el Centro Cultural Clavijero; todos en México. Fue docente en la Universidad del Claustro de Sor Juana, la Escuela Nacional de Conservación, Restauración y Museografía del Instituto Nacional de Antropología e Historia (ENCRYM-INAH), y en la Universidad Nacional Autónoma de México (UNAM); todas en México. Ha sido galardonada con el Premio INAH "Paul Coremans" (2000). En el 2008 recibió el apoyo "Richard Gilder" del American Museum of Natural History (EE. UU.) y, en el 2015, el Southwest Book Award por la Border Regional Library Association (EE. UU.). Actualmente es directora de la Colección y Registro del Museo Morelense de Arte Contemporáneo (MMAC) "Juan Soriano", en México.

Postulado/Submitted: 17.03.2017

Aceptado/Accepted: 08.06.2017

Publicado/Published: 15.07.2017 